\title{
THE EFFECTIVENESS OF SELECTED BIOLOGICAL CONTROL AGENTS IN CONTROLLING Ganoderma boninense
}

\author{
ARNNYITTE ALEXANDER ${ }^{1}$, RACHEAL KHAI SHYEN LO ${ }^{2}$ AND KHIM PHIN CHONG ${ }^{1,2 *}$
}

${ }^{1}$ Biotechnology Programme, Faculty of Science and Natural Resources, Universiti Malaysia Sabah, 88400 Jalan UMS, Kota Kinabalu, Sabah, Malaysia. ${ }^{2}$ FGV Chair of Sustainable Oil Palm Management, Faculty of Sustainable Agriculture, Universiti Malaysia Sabah, Sandakan Campus, Mile 10, Sg. Batang, 90000 Sandakan, Sabah, Malaysia.

*Corresponding author: chongkp@ums.edu.my

Submitted final draft: 20 October $2020 \quad$ Accepted: 27 November $2020 \quad$ http://doi.org/10.46754/jssm.2021.08.011

\begin{abstract}
This study aims to investigate the combination of biological control agents in managing Ganoderma boninense, the causal pathogen of Basal Stem Rot (BSR) disease in oil palm. The effectiveness of biological control agents (BCA) namely T1, T2 and T3 in managing BSR disease was tested and evaluated in the nursery and the field. Assessment on the disease progression of artificial Ganoderma inoculated oil palm seedlings based on disease severity (DSI) and bole severity index (BSI) was observed and recorded. The percentage of disease incidence (DI) was calculated for each treatment. Root and trunk tissue samples of the treated oil palms were collected and analyzed for their ergosterol content using High Performance Liquid Chromatography (HPLC) and plated on GSM. The findings showed BCA-based products are unable to prevent BSR infection in nursery trials. Nonetheless, if ergosterol content is taken as a representative of Ganoderma biomass in the oil palm tissue, the progression of the pathogen has been disrupted by the BCA. A longer observation period and additional parameters shall be taken in future studies to further validate the potential of these $\mathrm{BCA}$.
\end{abstract}

Keywords: Basal stem rot, oil palm, Ganoderma boninense, soil microbes, biological control agents.

\section{Introduction}

Oil palm is one of the most important plantation crops cultivated in South East Asia. However, the oil palm industry is threatened by Basal Stem Rot (BSR) disease caused by Ganoderma boninense (Chong et al., 2017). It can kill more than 80 percent of stands by the time they are halfway through their normal economic life. High incidence of BSR results in economic losses due to zero yield from dead palms and significantly reduced weight and number of fruit bunches in severely infected palms. To date, numerous management strategies have been attempted for BSR, including cultural practices (soil drenching, clean clearing, crop rotation, fallow period, burning and windrowing), chemical application, mechanical practices (surgery), biological control and effort in developing resistant genotypes, but with many uncertainties (Chong et al., 2012; Tay \& Chong (2016). Alternative technology or approach that could control Ganoderma and be synergistically environmentally friendly is worth looking into as a means to sustainable oil palm production. Soil microbes are important in maintaining soil fertility, stabilizing the ecosystem and preventing excessive growth of soil-borne pathogens (Alexander \& Chong, 2014). It has been reported that many species of microorganisms, including bacteria, fungi and actinomycetes, can be effective control agents of plant disease. Pseudomonas aeruginosa has been shown to improve plant growth and is effective in controlling Ganoderma (Lim et al., 2019; Muniroh et al., 2019), Trichoderma harzianum and Gliocladium viride were reported to reduce BSR disease incidence (Susanto et al., 2005) while Streptomyces spp. was reported to release antimicrobial compounds such as ribostamycin, benzylmalic acid, landomycin B and and salinomycin, which may contribute to the antagonistic effect against Ganoderma (Lim et al., 2018). Some studies, such as by Suryanto 
et al., (2012) reported that chitinolytic bacteria, Bacillus amyloliquefaciens and Serratia marcescens were potential biocontrol agents in suppressing BSR. In this paper we report the effectiveness of three different biological control agents (BCA) products in controlling Ganoderma.

\section{Materials and Methods}

\section{Cultivation of Oil Palm Seedlings}

Two hundred certified disease-free germinated oil palm seeds were purchased from Sawit Kinabalu Sdn. Bhd, Sabah, Malaysia. The germinated seeds were planted in a nursery at Universiti Malaysia Sabah and watered once a day. After three months, approximately $3 \mathrm{~g}$ of Granular NPK fertilizer 15:15:6:4 was applied every fortnight.

\section{Preparation of Rubber Wood Block Inoculum}

Rubber wood blocks (RWBs) $12 \mathrm{~cm} \mathrm{x} 6 \mathrm{~cm}$ $\mathrm{x} 6 \mathrm{~cm}$ in size were autoclaved at $121{ }^{\circ} \mathrm{C}$ with 15 psi for 20 minutes and dried in the laminar flow overnight. All blocks were transferred into heat-resistant polypropylene bags with $100 \mathrm{~mL}$ of malt extract agar (MEA) as a supplementary nutrient for Ganoderma growth and autoclaved for another 20 minutes. After they have cooled, the RWBs in the polypropylene bags were rotated to ensure they were well covered with the agar before it solidified. The cooled blocks containing MEA were inoculated with Ganoderma plugs (size $8 \mathrm{~mm}$ ) taken from a culture of 10 days old and incubated for four weeks until the blocks were fully colonized with Ganoderma. These colonized blocks were then used as inoculum sources for the following artificial inoculation experiments.

\section{Artificial Inoculation of Ganoderma boninense on Oil Palm Seedlings}

Artificial inoculation of oil palm seedlings was conducted by transplanting seedlings into new polybags containing inoculated RWBs. A linch incision was made at the end of the root to aid infection. The roots of the seedlings were kept in contact with the RWBs to allow the infection. The basal part of the inoculated seedlings in polybags were covered with black net of $50 \%$ shade to accelerate the infection of Ganoderma, however, there was no shade to the upper part (foliar) of the seedlings to allow maximum light intensity for the seedlings to grow.

\section{Application of Biological Control Agents (BCA) Products}

All products were applied following their standard operating procedures. TR1 was packed in a set of easy-to-use effervescent tablets, containing mixture of Bacillus sp. and Trichoderma sp. Each set contains 10 tablets of Trichoderma (TRS) and 10 tablets of Bacillus $(\mathrm{BCS}++)$. For application in field, each one of TRS and BCS++ tablets was dissolved in 20 $\mathrm{L}$ of water. This solution was sprayed onto the soil around the selected palms using a fine high-pressure spray covering up to a 3 metre radius from the palm base. Approximately 800 $\mathrm{mL}$ of solution was applied onto each palm. For application in nursery, the tablets were dissolved in $20 \mathrm{~L}$ of tap water and approximately $800 \mathrm{~mL}$ was applied onto each seedling. The treatment was performed once a month until the end of trial period (for field trial and nursery curative trial). TR2 is a mixture of Lactobacillus, Nattobacillus and Saccharomyces cerevisiae and TR3 is a mixture of Bacillus, Pseudomonas, Trichoderma and Penicillium. The application was similar to TR1 except both TR2 and TR3 were available in liquid form and first dissolved in 20 and $40 \mathrm{~L}$ of tap water respectively.

\section{Assessment on The Effectiveness of Microbial Treatments in Nursery}

(a) Prevention of Ganoderma infection in seedlings

In order to test the ability of the BCA to prevent Ganoderma infection in seedlings, BCA products were applied on oil palm seedlings prior to inoculation. The BCA products were applied continuously for three months (800 $\mathrm{mL}$ each month as described earlier) before inoculation with Ganoderma. Assessment was 
done 6,12 and 14 months after the inoculation with the pathogen.

(b) Curative of Ganoderma infected seedlings In order to test the possibility of BCA products reducing Ganoderma colonization, oil palm seedlings were inoculated with Ganoderma before treatment with BCA. Inoculated seedlings were placed for two months in the nursery. To confirm the seedlings were successfully inoculated, control seedlings were uprooted after two months, the roots were rinsed under running tap water, air-dried, surface sterilized by rinsing with $90 \%$ ethanol, dissected for examination and root tissues were also placed on the Ganoderma
Selective Medium (GSM). When seedlings were confirmed to be infected by Ganoderma, BCA treatments were started. Assessment for the effectiveness of the treatments after inoculation was done after 6,12 and 14 months.

\section{Evaluation on Disease Development}

Symptoms of BSR infection in treated oil palm seedlings were observed and evaluated based on the formation of basidiomata, foliar symptoms and proportion of bole damages as according to disease severity index (DSI) (Abdullah et al., 2003) and bole severity index (BSI) (Nursabrina et al., 2012).

Table 1: Disease signs and symptoms of oil palm seedlings corresponding to the disease classes for determination of disease severity index (Abdullah et al., 2003)

\begin{tabular}{|c|c|}
\hline Disease class & Signs and symptoms \\
\hline 0 & $\begin{array}{l}\text { Healthy plants with green leaves without appearance of fungal mycelium on any part of } \\
\text { plants }\end{array}$ \\
\hline 1 & Appearance of white fungal mass on any part of plants, with or without chlorotic leaves \\
\hline 2 & Appearance of basidioma on any part of plants with chlorotic leaves ( 1 to 3 leaves) \\
\hline 3 & Formation of basidioma of any part of plants with chlorotic leaves ( $>3$ leaves) \\
\hline 4 & Formation of a well-developed basidioma and plants are dehydrated \\
\hline
\end{tabular}

The disease severity index (DSI) was calculated using the formula:

$$
\text { DSI }=\frac{\text { Number of seedlings in the rating } \mathrm{x} \text { rating number }}{\text { Total number of seedlings assessed } \mathrm{x} \text { highest rating }} \mathrm{X} 100
$$

Table 2: Internal symptoms assessment based on bole-tissue damage (Nursabrina et al., 2012).

\begin{tabular}{cl}
\hline Disease class & \multicolumn{1}{c}{ Signs and symptoms } \\
\hline 0 & Healthy \\
1 & up to $20 \%$ rotting of bole tissue \\
2 & $21 \%$ to $50 \%$ rotting of bole tissue \\
3 & $51 \%$ to $90 \%$ rotting of bole tissue \\
4 & over $90 \%$ rotting of bole tissue \\
\hline
\end{tabular}

The internal symptom of the bole tissues was calculated using the formula:

$$
\text { Bole severity index }=\frac{\text { Number of seedlings in the rating } \mathrm{x} \text { rating number }}{\text { Total number of seedlings assessed } \mathrm{x} \text { highest rating }} \times 100
$$




\section{Collection of Root and Trunk Tissues}

Oil palm seedling roots (from the nursery) were uprooted carefully and washed under running tap water to remove any unwanted materials. The cleaned roots were then sterilized with $90 \%$ ethanol to remove any saprophytic fungi on the roots' surface, rinsed with sterile water and air dried. The roots were then cut into smaller pieces of about $5 \mathrm{~cm}$ long, homogenized in a commercial blender and placed in clean zip-lock plastics for further use. The collection of trunk tissues (from the field) was done as described by Chong and Alexander (2014) with slight modifications. Two hundred infected (10 years old) palms in Pamol plantation, Sandakan, Sabah, Malaysia, were selected after a homogeneity screening test (selected palms had ergosterol content that were not statistically significant to each other at the beginning of the trial). The trunk tissue was collected at four points on each palm at an angle of $90^{\circ}$ to each other and 1 metre above the soil floor using a drill. These samples were analysed for their ergosterol content using High Performance Liquid Chromatography (HPLC) and plated on Ganoderma selective medium
(GSM). Additionally, 50 healthy palms were selected as a healthy control group.

\section{Evaluation on Ganoderma boninense Colonization Using Ergosterol Analysis and Quantification}

Ergosterol from oil palm seedling root and trunk tissue were extracted as described by Chong et al. (2012). Oil palm roots were harvested and homogenized using a commercial blender. Roots and trunk tissue samples $(100 \mathrm{mg})$ were extracted in methanol using a glass rod to physically crush the sample. The extract was centrifuged at $15,000 \mathrm{rpm}$ for $5 \mathrm{~min}$ and the supernatant was made up to $1.5 \mathrm{~mL}$ before being filtered through a $0.45 \mu \mathrm{m}$ acetate syringe tip. The filtrate was placed in a $1.5 \mathrm{~mL}$ HPLC vial and underwent HPLC.

\section{Disease Incidence}

The disease incidence (DI) caused by Ganoderma for seedlings treated with different treatments was evaluated based on the possible isolation of the fungi on GSM and the presence of ergosterol at a detectable level.

$$
\text { DI }=\frac{\text { Number of seedlings with fungi isolated on GSM and detectable ergosterol }}{\text { Total number of seedlings assessed }} \times 100
$$

\section{Experimental Design and Statistical Analysis}

All experiments were completely randomized design (CRD). Data was analyzed using oneway ANOVA (Analysis of Variance) using IBM SPSS statistics version 22. Significant differences among treatments were analyzed using Tukey test at $\mathrm{p}<0.05$ significant level.

\section{Results and Discussion}

Assessment on the Effectiveness of Microbial Treatments in Nursery (Prevention Assessment)

The efficacy of BCA treatments in preventing Ganoderma infection is shown in Table 3. For up to 12 months, T3 formulation treatment on seedlings inoculated with Ganoderma showed the best preventive action against the disease, with lowest DSI and BSI values. However, at month 14, seedlings treated with T3 reached $100 \%$ DSI and $90.63 \%$ BSI. For the first 12 months of assessment, T3 seems to have the ability to delay Ganoderma colonization, however, this potential was easily overcome by the pathogen during the last two months of observation. An insight into the colonization of this pathogen in oil palm seedlings for up to six months was provided by Alexander et al. (2017) which demonstrated root tissues inoculated with the pathogen were severely damaged with complete breakdown of oil palm root cells. The Ganoderma mycelium colonized the root surface directly, progressed through the cortex and altered the root cells structure. All infected root tissues show similar physical damage. On the other hand, Rees et al. (2009) through 
their experiment on five-month-old oil palm seedlings revealed that $G$. boninense produces abundant, enlarged, intracellular hyphae, mainly in the inner cortical cells during the early stage of oil palm Ganoderma colonization. The attack was later followed by the breakdown of cortical cell walls, where all wall layers were attacked, resulting in the complete breakdown of the cell wall, including the middle lamella and inter and intracellular and intramural colonization of the oil palm root.However, the stele and lacunae were not invaded during the early stages of root infection. Both findings revealed the massive destruction caused by $G$. boninense during the $5^{\text {th }}$ or $6^{\text {th }}$ month after inoculation. In the current work, the ability of BCA treatments, especially T3, to suppress the disease and bole severity up to $12^{\text {th }}$ month may due to the capability of Bacillus, Pseudomonas and Penicillium in producing antifungal compounds against the growth of $G$. boninense (Alexander et al,. 2017; Lim et al., 2019 a \& b). In addition, Trichoderma, which is present in T3, also has the ability to coil and kill the pathogen (Alexander et al,. 2017). Though, the ability of $G$. boninense to overwhelm the BCA at month 14 and cause a drastic increase in disease and bole severity may need further investigation.

T1 exhibited the lowest BSI value compared to T2 and T3. However, no significant difference was observed in DSI values between $\mathrm{T} 2$ and T1 treated seedlings at month 14 . The DSI and
BSI values for infected control seedlings also reached $100 \%$ by the end of the experiment. Colonization of Ganoderma can be confirmed by the presence of ergosterol in infected roots of oil palm seedlings and the fungal growth on GSM.

Control seedlings inoculated with Ganoderma were infected and accumulated $48.493 \mu \mathrm{g} / \mathrm{g}$ of ergosterol in the extracted roots. Meanwhile, inoculated seedlings treated with T1, T2 and T3 also showed $100 \%$ of DI, but with lower ergosterol content $(25.418 \mu \mathrm{g} / \mathrm{g}$, $15.081 \mu \mathrm{g} / \mathrm{g}$ and $15.555 \mu \mathrm{g} / \mathrm{g}$ respectively) and T2 recorded the lowest DI. At month 12 (Figure 1-b), ergosterol content in control seedlings increased to more than double initial ergosterol content. Seedlings treated with T1, T2 and T3 showed increased ergosterol content with $37.645 \mu \mathrm{g} / \mathrm{g}, 30.674 \mu \mathrm{g} / \mathrm{g}$ and $37.21 \mu \mathrm{g} / \mathrm{g}$, respectively. At month 14 (Figure 1-c), the DI percentage in all treatments was similar to previous intervals. Ergosterol content increased considerably in all treated samples; however, the lowest was recorded in T1 treated samples at $57.457 \mu \mathrm{g} / \mathrm{g}$. Similar results were reported previously, where treated seedlings showed increment in DI over time, however, with less Ganoderma colonization based on the ergosterol amount in the nursery trial (Alexander et al., 2017). Accidental root injuries caused during Ganoderma inoculation may facilitate an open route for pathogen penetration and colonization.

Table 3: Disease severity index (DSI) and bole severity index (BSI) in prevention of Ganoderma infection trial. Biological control agents were applied for three months before Ganoderma inoculation. DSI and BSI were taken 6, 12 and 14 months after inoculation.

\begin{tabular}{|c|c|c|c|c|c|c|}
\hline \multirow{3}{*}{ Treatment } & \multicolumn{3}{|c|}{ Disease severity index $(\%)$} & \multicolumn{3}{|c|}{ Bole severity index (\%) } \\
\hline & \multicolumn{3}{|c|}{ Month } & \multicolumn{3}{|c|}{ Month } \\
\hline & 6 & 12 & 14 & 6 & 12 & 14 \\
\hline $\mathrm{T} 1$ & $3.13^{\mathrm{b}} \pm 0.16$ & $34.38^{b} \pm 1.67$ & $93.75^{\mathrm{a}} \pm 4.79$ & $3.13^{\mathrm{b}} \pm 0.16$ & $56.25^{b} \pm 2.78$ & $65.63^{a} \pm 2.94$ \\
\hline $\mathrm{T} 2$ & $3.13^{\mathrm{b}} \pm 0.16$ & $31.25^{\mathrm{ab}} \pm 1.48$ & $93.75^{\mathrm{a}} \pm 4.79$ & $0.00^{\mathrm{a}} \pm 0.00$ & $75.00^{\mathrm{d}} \pm 3.82$ & $81.25^{\mathrm{b}} \pm 3.58$ \\
\hline $\mathrm{T} 3$ & $0.00^{\mathrm{a}} \pm 0.00$ & $25.00^{\mathrm{a}} \pm 1.08$ & $100.00^{\mathrm{b}} \pm 0.00$ & $0.00^{\mathrm{a}} \pm 0.00$ & $0.69^{\mathrm{a}} \pm 0.04$ & $90.63^{\mathrm{c}} \pm 4.27$ \\
\hline $\begin{array}{l}\text { Infected } \\
\text { (Control) }\end{array}$ & $6.25^{\mathrm{c}} \pm 0.28$ & $84.38^{\mathrm{c}} \pm 3.96$ & $100.00^{\mathrm{b}} \pm 0.00$ & $0.00^{\mathrm{a}} \pm 0.00$ & $65.63^{\mathrm{c}} \pm 3.34$ & $100.00^{\mathrm{d}} \pm 0.00$ \\
\hline
\end{tabular}

DSI and BSI are shown in the average of symptoms on a scale from 0 to 4 (mean \pm SD). $n=6$ seedlings per treatment/month. DSI and BSI in each column with different letters are significantly different at $\mathrm{p} \leq 0.05$ within interval. 
Application of BCA products prior to disease development may have induced host plant resistance, thus controlling the population of the pathogen within host cells (Elad, 2003). Continuous application of BCA products may have resulted in significant reduction in colonization, however, in the case of the current $\mathrm{BCA}$ products, further investigation is needed to confirm this.

\section{Assessment of the Effectiveness of Microbial Treatments in Nursery (Curative Assessment)}

The efficacy of BCA treatments in reducing Ganoderma colonization is shown in Table 4. At month 6, T1 and T3 treated seedlings showed significant reduction of the DSI and BSI respectively. However, at month 12, DSI and BSI values for all treatments increased significantly, with seedlings treated with $\mathrm{T} 2$ recording the lowest DSI while T3 exhibited the lowest BSI value. After 14 months, the DSI for T1, T3 and control seedlings have reached $100 \%$, except seedlings treated with T2 (93.75\%). However, evaluation on BSI percentage shows that all seedlings have reached $100 \%$.

Assessment on the pathogen colonization based on ergosterol analysis and DI are given in Figure 2. Up to month $12 \mathrm{~T} 1$ treated seedlings recorded a significantly lower ergosterol content compared to T2 and T3 (Figure 2-a, 2-b). However, a comparison between $\mathrm{T} 3$ and T2 treated seedlings shows that the latter treatment was more efficacious, giving a lower amount of ergosterol content. At month 14, no reduction of DI was observed in all treated seedlings. However, seedlings that have been treated with $\mathrm{T} 1$ recorded significantly lower ergosterol content $(6.48 \mu \mathrm{g} / \mathrm{g})$ compared to $\mathrm{T} 2$ $(14.816 \mu \mathrm{g} / \mathrm{g}$ ) and $\mathrm{T} 3(23.925 \mu \mathrm{g} / \mathrm{g}$ ) (Figure 2-c). Although the DI throughout the assessment remains unchanged, Ganoderma colonization in all treated seedlings was lower compared to control seedlings based on the ergosterol content. A study by Alexander et al. (2017)

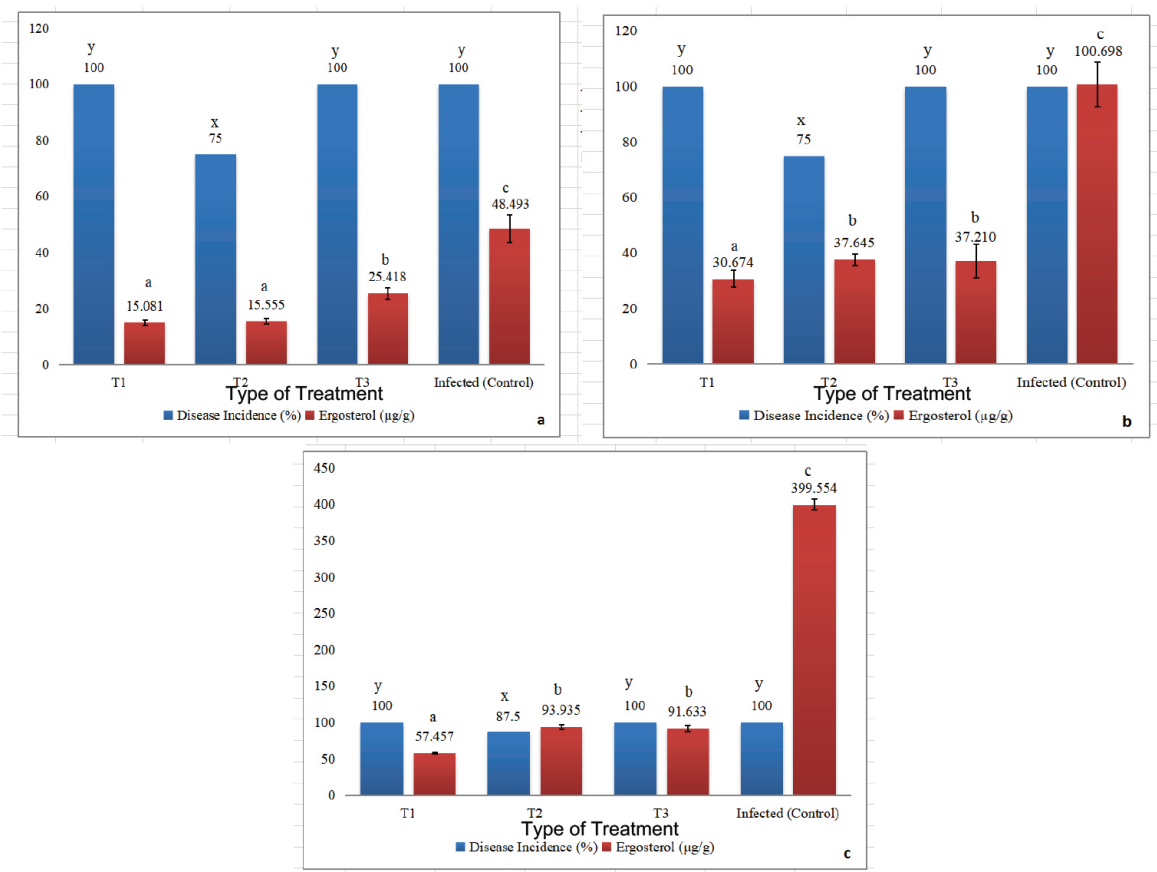

Figure 1: Disease incidence (DI) and ergosterol content of oil palm seedlings in prevention of Ganoderma infection trial. Biological control agents were applied for three months before Ganoderma inoculation. DI and ergosterol content were taken (a) 6 months, (b) 12 months, (c) 14 months after inoculation. T denotes treatment. No ergosterol detected in Healthy (Control) palms 
Table 4: Disease severity index (DSI) and bole severity index (BSI) of oil palm seedlings in curative of Ganoderma infection trial. Biological control agents were applied for two months after seedlings were found infected by Ganoderma. DI and ergosterol content were taken (a) 6 months, (b) 12 months, (c) 14 months after respective treatments were stopped

\begin{tabular}{|c|c|c|c|c|c|c|}
\hline \multirow{3}{*}{ Treatment } & \multicolumn{3}{|c|}{ Disease severity index (\%) } & \multicolumn{3}{|c|}{ Bole severity index (\%) } \\
\hline & \multicolumn{3}{|c|}{ Month } & \multicolumn{3}{|c|}{ Month } \\
\hline & 6 & 12 & 14 & 6 & 12 & 14 \\
\hline $\mathrm{T} 1$ & $18.75 \mathrm{a}$ & $81.25 b$ & $100 \mathrm{~b}$ & $9.375 b$ & $71.875 b$ & $100 \mathrm{a}$ \\
\hline $\mathrm{T} 2$ & $25 b$ & $71.875 \mathrm{a}$ & $93.75 \mathrm{a}$ & $9.375 b$ & $71.875 b$ & $100 \mathrm{a}$ \\
\hline $\mathrm{T} 3$ & $25 b$ & $81.25 b$ & $100 \mathrm{~b}$ & $3.125 \mathrm{a}$ & $59.375 \mathrm{a}$ & $100 \mathrm{a}$ \\
\hline $\begin{array}{c}\text { Infected } \\
\text { (Control) }\end{array}$ & $28 \mathrm{~b}$ & $93.75 \mathrm{c}$ & $100 \mathrm{~b}$ & $25 \mathrm{c}$ & $84.375 \mathrm{c}$ & $100 \mathrm{a}$ \\
\hline
\end{tabular}

* DSI in each column with different letters is significantly different at $\mathrm{p} \leq 0.05$ within interval.

also reported that microbial treatments gave significant reduction of DI and ergosterol accumulation in treated-infected oil palms compared to untreated-infected palms. Similarly, other experiments under greenhouse conditions revealed a combination of Pseudomonas strains and $B$. subtilis was found to inhibit the disease severity of Sclerotium rolfsii and Rhizoctonia solani on Capsicum annum (Abeysinghe, 2009).

\section{Assessment of the Effectiveness of Microbial Treatments inField}

The DI (determined by fungi growth on GSM and ergosterol content) before treatment is shown in

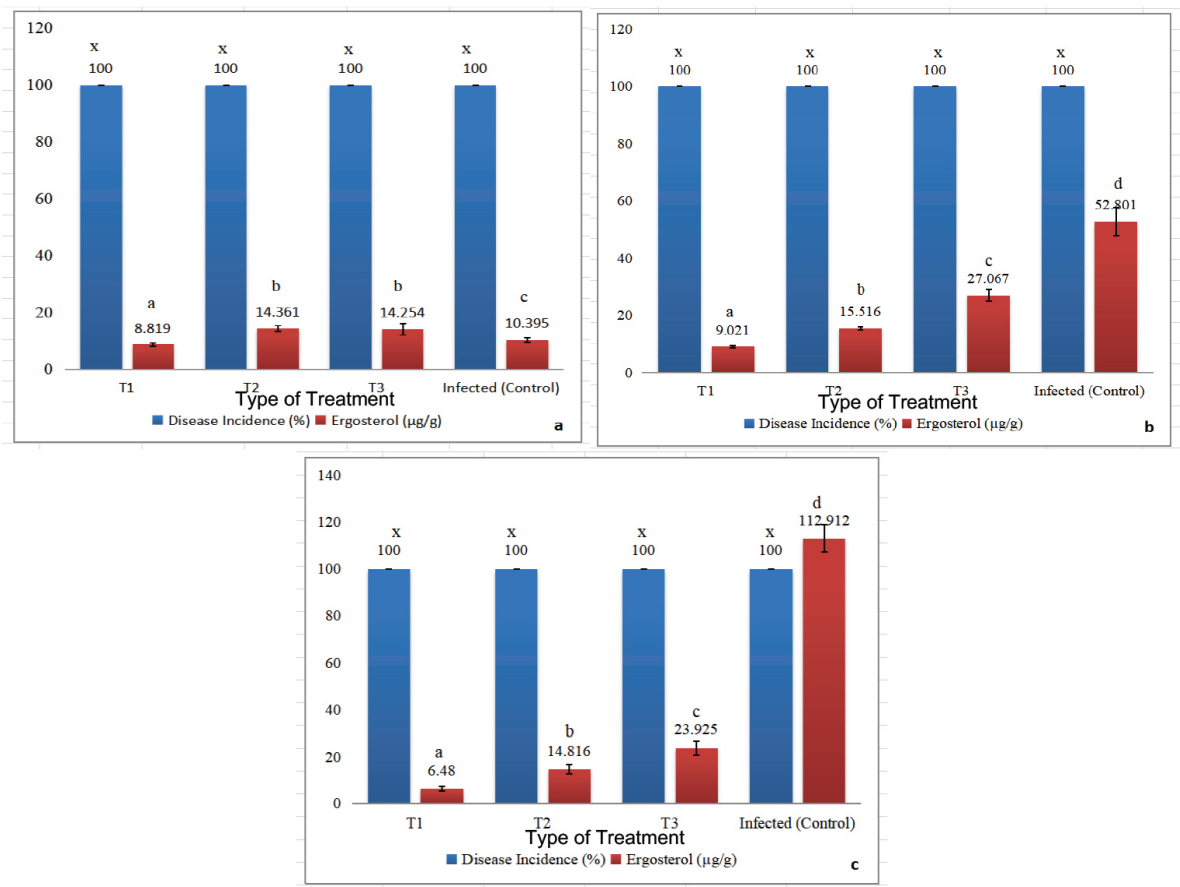

Figure 2: Disease incidence (DI) and ergosterol content of oil palm seedlings in curative of Ganoderma infection trial. Biological control agents were applied for two months after seedlings were found infected by Ganoderma. DI and ergosterol content were measured (a) 6 months, (b) 12 months, (c) 14 months after respective treatments were stopped. $\mathrm{T}$ denotes treatment. No ergosterol detected in Healthy (Control) palms 
Figure 3 (a). No significant differences in DI and ergosterol content in palms were selected from the beginning of the trial. Two types of control were also evaluated; i) Untreated/Infected and ii) Untreated/healthy palms. At month 6 (Figure 3-b), the DI in control (untreated/infected) palms remained at $100 \%$, meanwhile, palms treated with T1, T2 and T3 showed significant decrement, to $88 \%, 86 \%$ and $92 \%$ respectively. The ergosterol content in all treated palms increased significantly; however, $\mathrm{T} 1$ recorded the lowest increment compared to other treatments. At month 12 (Figure 3-c), palms treated with $\mathrm{T} 1, \mathrm{~T} 2$ and $\mathrm{T} 3$ showed significant recovery in comparison to controls, down to $62 \%, 72 \%$ and $84 \%$ respectively with the former showing the lowest reduction. In terms of ergosterol content, T1 treated palms showed the greatest reduction. At month 14 (Figure 3-d), T2 treated palms saw reduced fungal colonization down to $60 \%$, with a parallel reduction in ergosterol to $30 \%$ concentration. T1 treated palms also showed significant recovery, with fungal colonies down to $62 \%$ at the end of the observation period. This treatment also reduced the amount of ergosterol by $12 \%$ compared to before treatment. Although palms treated with T3 showed slight increment of ergosterol compared to before treatment, the DI still went down to $88 \%$ throughout the trial. The concentration of ergosterol in control (untreated/infected), increased tremendously during this observation period and the DI was at $100 \%$ at the end of the experiment. It is likely that biocontrol efficacy under natural conditions is even more variable than those reported in controlled studies, as often observed in field trials (Xu et al., 2011). Environmental parameters, such as abiotic and biotic factors, as well as other factors, such as method and timing of applications, may influence the biological control efficacy of biocontrol agents (Behzad et al., 2008; McSpadden \& Fravel, 2002).

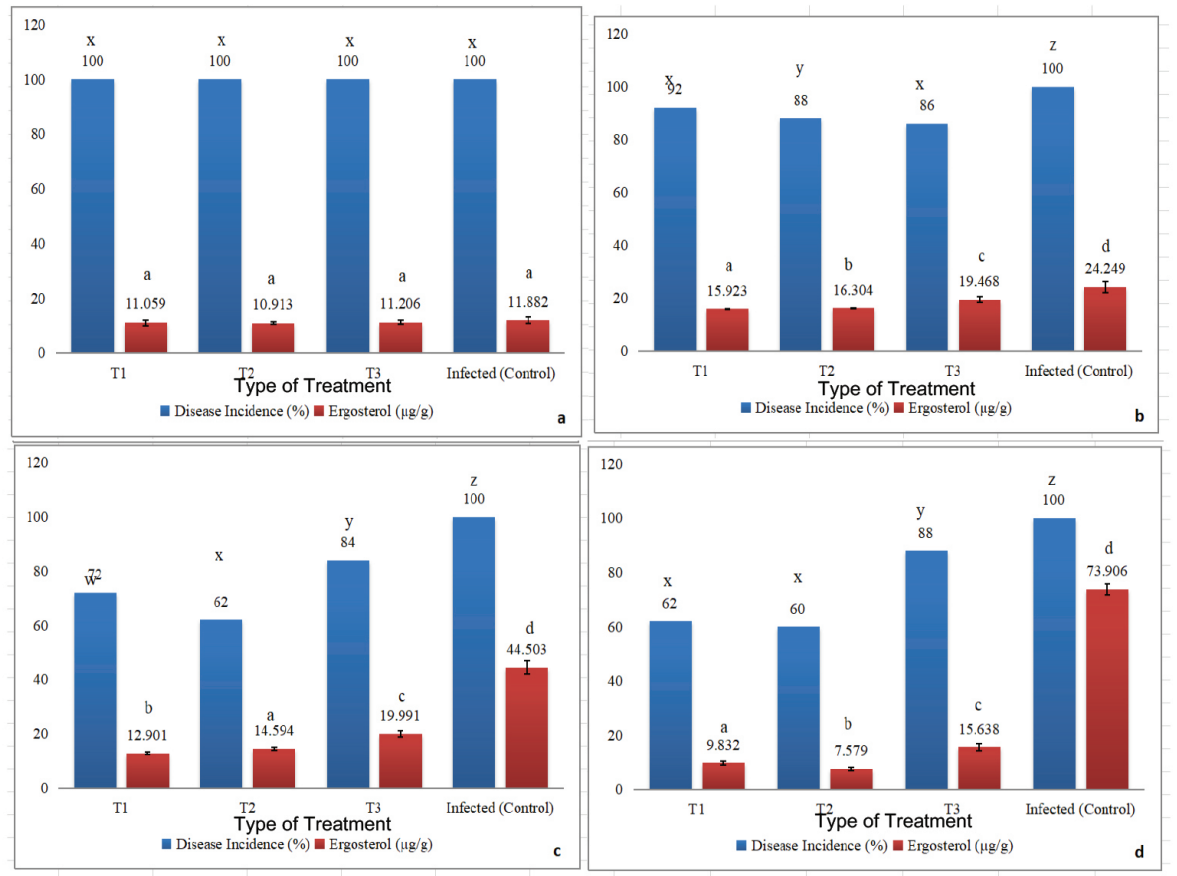

Figure 3: Disease incidence (DI) and ergosterol content of palms in field trial at (a) 0 month (b) six months, (c) 12 months, (d) 14 months. DI was determined by growth Ganoderma on GSM and detectable ergosterol amount. T denotes treatment. No ergosterol detected in Healthy (Control) palms 
Overall, throughout the study, all BCA products were able to reduce the pathogen colonization rate compared to control seedlings. Disease suppression is due to a specific interaction between the pathogen and its antagonist. Its occurrence in natural systems may also vary from time to time. Some possible mechanisms used by antagonist microbes to reduce damage from pathogens include environmental competition and displacement of pathogens, production of cell wall degrading enzymes, general enhancement of plants to resist pathogen infection, and possible inhibition of fungal growth via production of antifungal compounds (Heydari \& Pessarakli, 2010; Pal \& Gardener, 2006).

\section{Conclusion}

The present work shows that BCA-based products (T1, T2 and $\mathrm{T} 3$ ) are unable to prevent BSR infection in a nursery trial. Application of these products is able to suppress and reduce colonization of Ganoderma in the nursery and the field if ergosterol content is taken as a representative of Ganoderma biomass in oil palm tissue. However, a longer observation period, such as up to 2 years and with additional fruit bunch data shall be taken in the future to further validate the potential of these BCA. Biological control using fungal and bacterial antagonists to manage BSR disease seems to be a promising alternative strategy in the long term. Incorporation of good cultural practices will provide the foundation for successful BSR management by providing a fertile growing environment for the crop.

\section{Acknowledgements}

This research has been jointly funded by IOI Corporation Bhd, One Good Earth Sdn Bhd and Organica Biotech Sdn Bhd under grant number GL00105.

\section{References}

Abdullah, F., Ilias, G. N. M., Nelson, M., Nur Ain Izzati, M. Z., \& Umi Kalsom, Y. (2003). Disease assessment and the efficacy of Trichoderma as a biocontrol agent of basal stem rot of oil palms. Research Bulletin Science Putra, 11, 31-33.

Abeysinghe, S. (2009). Efficacy of combined use of biocontrol agents on control of Sclerotium rolfsii and Rhizoctonia solani of Capsicum annum. Archives of Phytopathology and Plant Protection, 42(3), 221-227.

Alexander, A., Abdullah, S., Rossall, S., \& Chong, K. P. (2017). Evaluation of the efficacy and mode of action of biological control for suppression of Ganoderma boninense in oil palm. Pakistan Journal of Botany, 49(3), 1193-1199.

Alexander, A., \& Chong, K. P. (2014). Combination of biological control agents in suppressing colonization of Ganoderma boninense of basal stem rot. American-Eurasian Journal of Sustainable Agriculture, 8(7 Special Issue 2), 1-7.

Behzad, H., Mousa, T., Mohammad, R. M., \& Mahdi, D. (2008). Biological potential of some Iranian Trichoderma isolates in the control of soil borne plant pathogenic fungi. African Journal of Biotechnology, 7, 967972.

Chong, K. P., \& Alexander, A. (2014). Early detection of Ganoderma in oil palm: A field guide. Kota Kinabalu, Sabah, Malaysia: Universiti Malaysia Sabah.

Chong, K. P., Atong, M., \& Rossall, S. (2012). The roles of syringic, caffeic and 4hydroxybenzoic acids in Ganodermaoil palm interaction. Asian Journal of Microbiology, Biotechnology and Environmental Sciences, 14(2), 157-166.

Chong, K. P., Dayou, J., \& Alexander, A. (2017). Detection and control of Ganoderma boninense in oil palm crop. Springer International Publishing. 
Elad, Y. (2003). Biocontrol for foliar pathogens: Mechanisms and application. Communications in Agricultural and Applied Biological Sciences, 68(4), 17-24.

Heydari, A., \& Pessarakli, M. (2010). A review on biological control of fungal plant pathogens using microbial antagonists. Journal of Biological Sciences, 10(4), 273290.

Lim, P. H., Gansau, J. A., \& Chong, K. P. (2019a). Biocontrol of basal stem rot pathogen Ganoderma boninense by Pseudomonas aeruginosa. Bangladesh Journal of Botany, 48(2), 209-215.

Lim, P. H., Gansau, J. A., \& Chong, K. P. (2019b). Preliminary screening and characterization of fungi isolated from forest soil as biocontrol agent against Ganoderma boninense. Malaysian Journal of Microbiology, 15(2), 103-110.

Lim, P. H., Gansau, J. A., \& Chong, K. P. (2019). Streptomyces spp as a potential biocontrol agent against Ganoderma boninense of basal stem rot in oil palm. Journal of Oil Palm Research ,30(2), 265-275.

McSpadden Gardener, B. B., \& Fravel, D. R. (2002). Biological control of plant pathogens: Research, commercialization, and application in the USA. Plant Health Progress, viewed 3 May 2002, <http://www. apsnet.org/publications/apsnetfeatures/ Pages/BioControl.aspx $>$.

Muniroh, M. S., Nusaibah, S. A., Vadamalai, G., \& Siddique, Y. (2019). Proficiency of biocontrol agents as plant growth promoters and hydrolytic enzyme producers in Ganoderma boninense infected seedlings. Current Plant Biology, 20(100116), 1-9.

Nur Sabrina, A. A, Sariah, M., \& Zaharah, A. R. (2012). Suppression of basal stem rot progress in oil palm (Elaeis guineensis) after copper and calcium supplementation. Pertanika Journal of Tropical Agricultural Science, 35, 13-24.

Pal, K. K., \& Gardener, B. M. (2006). Biological control of plant pathogens. The Plant Health Instructor, APSnet, 5.

Suryanto, D., Wibowo, R. H., Siregar, E. B., \& Munir, E. (2012). A possibility of chitinolytic bacteria utilization to control basal stem disease caused by Ganoderma boninense in oil palm seedling. African Journal of Microbiology Research, 6(9), 2053-2059.

Susanto, A., Sudharto, P. S., \& Purba, R. Y. (2005). Enhancing biological control of basal stem rot disease (Ganoderma boninense) in oil palm plantations. Mycopathologia, 159, 153-157.

Tay, Z. H., \& Chong, K. P. (2016). The potential of papaya leaf extract in controlling Ganoderma boninense. IOP Conf. Series: Earth and Environmental Science, 36(2016) 012027: 1-7. doi:10.1088/17551315/36/1/012027.

Xu, X. M., Jeffries, P., Pautasso, M., \& Jeger, M. J. (2011). Combined use of biocontrol agents to manage plant diseases in theory and practice. Phytopathology, 101, 10241031. 